Revista de
Economild
Contemporâned

\title{
A NOVA CONFIGURAÇÃO DA ESTRUTURA PRODUTIVA DO SETOR SUCROENERGÉTICO BRASILEIRO: PANORAMA E PERSPECTIVAS
}

\author{
Junior Ruiz Garcia ${ }^{a}$ \\ Divina Aparecida Leonel Lunas Lima \\ Adriana Carvalho Pinto Vieira ${ }^{c}$
}

aPrograma de Pós-graduação em Desenvolvimento Econômico, Departamento de Economia, Universidade Federal do Paraná (UFPR).

'Programa de Pós-graduação em Territórios e Expressões Culturais da Universidade Estadual de Goiás (UEG).

'Programa de Pós-graduação em Desenvolvimento Socioeconômico da Universidade do Extremo Sul

Catarinense (UESC) e INCT/PPED da Universidade Federal do Rio de Janeiro (UFRJ).

Artigo recebido em 19/12/2013 e aprovado em 11/06/2015.

RESUMO: O setor sucroenergético brasileiro tem atraído investimentos estrangeiros de forma acentuada desde 2003/2004. Os fatores que estimularam este movimento estão relacionados às perspectivas de consolidação de um mercado internacional, a expansão da demanda externa e interna e a elevação do preço do combustível fóssil. Outro fator que contribui para a atratividade do capital externo é a competitividade do etanol brasileiro em relação às demais matérias-primas utilizadas em outros países. Este trabalho tem por objetivo caracterizar e analisar a nova configuração da estrutura produtiva do setor sucroenergético brasileiro após o movimento de entrada do capital externo. A presença do capital externo pode alterar a dinâmica do setor, levando até ao fortalecimento dos elos na cadeia produtiva (trade linkages). Além disso, a presença do capital externo a partir da entrada de empresas transnacionais pode elevar as atividades de pesquisa e desenvolvimento tecnológico no setor sucroenergético, dando um novo impulso.

PALAVRAS-CHAVE: agroenergia; organização industrial; transnacionais; investimentos direto estrangeiro.

CLASSIFICAÇÃO JEL: F21; L22; L23.

Correspondência para: Adriana Carvalho Pinto Vieira.

E-mail: dricpvieira@unesc.net 


\title{
THE NEW CONFIGURATION OF PRODUCTION STRUCTURE BRAZILIAN SUGARCANE INDUSTRY: OVERVIEW AND PROSPECTS
}

\begin{abstract}
The Brazilian sugarcane industry has attracted foreign investment since 2003/2004. The factors, that have stimulated this movement, are related to the prospects for the consolidation of an international market ethanol, expanding external and internal demand and the rising price of fossil fuel. Another factor is the competitiveness of Brazilian ethanol compared with other raw materials used in other countries. This paper aims to characterize and analyze the new configuration of the productive structure of the Brazilian sugarcane industry after the movement in foreign capital. The presence of foreign capital can change the dynamics of the sector, leading to the strengthening of the links in the production chain (trade linkages). Furthermore, the presence of foreign capital from the entry of transnational enterprises can raise research and technological development in the sugarcane industry, giving a new impulse.
\end{abstract}

KEYWORDS: agro-energy; industrial organization; transnational enterprises; foreign direct investment. 


\section{INTRODUÇÃO}

A queda do preço do barril de petróleo no início da década de 1990 e o aumento dos preços do açúcar contribuíram para a estagnação da produção brasileira de etanol anidro e hidratado, que permaneceu, ao longo desse período, em 11 bilhões de litros ao ano (Garcia, 2007). Esse quadro levou à redução dos investimentos e ao sucateamento parcial do parque industrial instalado ao longo da década de 1980.

Contudo, o início da produção e comercialização de veículos bicombustíveis (flexfuel) no Brasil entre 2003/2004, a elevação do preço do barril de petróleo, a intensificação das discussões sobre o aquecimento global e o papel dos combustíveis fósseis na problemática ambiental alteraram profundamente as perspectivas do setor sucroenergético (Garcia, 2007; CGEE, 2009; Kohlhepp, 2010). Segundo Macedo (2007), a capacidade de redução das emissões de gases de efeito estufa do etanol produzido a partir da cana-de-açúcar é extremamente elevada em função de ser uma fonte renovável e por apresentar um balanço energético da ordem de 8,9, muito superior ao etanol de milho produzido pelos EUA, da ordem de 1,3. Assim, esse novo cenário abriu novas perspectivas sobre o futuro da produção de etanol (Macedo, 2007), especialmente para o Brasil, onde o crescimento médio anual da produção de cana-de-açúcar foi de 10,4\% entre os anos safra 2000/2001 e 2008/2009 (Unica, 2011a).

No período recente, o setor sucroenergético brasileiro tem atraído investimentos estrangeiros de forma acentuada. Na safra 2010/2011, a participação relativa das empresas controladas pelo capital estrangeiro na capacidade total de moagem do setor alcançou 25,5\% ante 11,9\% na safra 2007/2008 (Nastari, 2010). Esse movimento de entrada do capital externo está relacionado à consolidação do uso do etanol como fonte alternativa ao combustível fóssil no Brasil, e que apresenta forte tendência a sua aceitação no mercado internacional a partir da abertura de novos mercados, por exemplo, na União Europeia, Coreia do Sul, EUA, Japão e Caribe (Unica, 2011b).

Neste sentido, os fatores que podem explicar a entrada de capital externo no setor sucroenergético brasileiro são as estimativas favoráveis de consolidação de um mercado internacional para o etanol, demanda em franca expansão, bem como a entrada de novas rotas tecnológicas, como, por exemplo, o etanol de segunda e terceira geração ${ }^{1}$, além da produção de biopolímeros² (Macedo, 2007; Schenberg, 2010). Nos últi-

1 Os biocombustíveis para transportes podem ser categorizados como de primeira geração, composta de culturas alimentares (trigo, cana-de-açúcar, beterraba e sementes oleaginosa), de segunda geração, composta por materiais lignocelulósicos (palha de cereais, colmos de milho, etc.), e os de terceira geração, composta por algas (McCormick, 2010).

2 São materiais biocompatíveis e biodegradáveis que têm por objetivo substituir parcial ou totalmente o uso de plásticos de origem petroquímica (Schenberg, 2010). 
mos dez anos, a produção mundial de biocombustíveis aumentou significativamente. Isso ocorreu principalmente em função do aporte de incentivos governamentais (Sorda et al., 2010). Diversos países, como EUA e membros da União Europeia, em especial a Alemanha, têm estimulado a pesquisa, produção e o uso de combustíveis renováveis em seus territórios, a partir de plataformas estratégicas e da implantação de políticas específicas para a inclusão de biocombustíveis à gasolina (Sorda et al., 2010; Tye, et al., 2011; Koizumi, 2013). Assim, manter o controle do ambiente político em rápida mutação, em que os biocombustíveis sejam produzidos, consumidos e comercializados, é um desafio à medida que novas políticas estão sendo promulgadas rapidamente por diferentes países, e a legislação anterior é frequentemente modificada (Carriquiry e Timilsina, 2011).

Outro fator que contribui para a atração de capital externo é a alta competitividade que o etanol brasileiro, produzido a partir de cana-de-açúcar, tem em relação às demais matérias-primas, em especial ao etanol de milho e de beterraba produzido nos Estados Unidos e na Europa, respectivamente (Kohlhepp, 2010). A elevada produtividade do etanol de cana-de-açúcar, com uma média de 3,5 a 7 mil litros por hectare (Mapa, 2013), garante um produto competitivo e atrativo para sua comercialização no mercado internacional, acrescentando ainda a tendência de redução dos custos de transporte.

Diante do que foi exposto, o objetivo deste trabalho é caracterizar e analisar a configuração da estrutura produtiva do setor sucroenergético brasileiro após a entrada de investimentos estrangeiros a partir de aquisições, fusões e construções de novas plantas industriais a partir da retomada do setor. $\mathrm{O}$ trabalho busca responder às seguintes questões: i) como a entrada do capital externo alterou a organização estrutural do setor sucroenergético brasileiro? ii) quais são as implicações da entrada do capital externo na dinâmica do setor sucroenergético brasileiro?

Este trabalho está organizado em quatro seções além desta introdução. A primeira seção apresenta uma discussão teórica sobre a organização industrial. A segunda busca apresentar uma breve caracterização da estrutura agroindustrial do setor sucroenergético brasileiro. Na sequência se discute o movimento de entrada do capital externo no setor sucroenergético brasileiro. A última seção tem por objetivo apresentar as considerações gerais, com ênfase nas perspectivas e desafios postos ao setor sucroenergético brasileiro em função da nova configuração instalada a partir da entrada do capital externo.

\section{ESTRUTURA, ORGANIZAÇÃO INDUSTRIAL E INVESTIMENTO DIRETO ESTRANGEIRO}

A partir de uma visão global da organização industrial de um país, a competição externa pode afetar de maneira significativa sua dinâmica setorial e nacional. No cenário 
de relativa mobilidade dos fatores, em função do avanço da globalização dos mercados, impulsionada pela redução dos custos de movimentação das mercadorias e dos fatores, o comportamento das empresas passou a sofrer influência direta do ambiente externo, das políticas macroeconômicas, do poder político, das instituições, dos avanços tecnológicos que apresentam acelerada difusão nos mercados, concorrência internacional, fornecedores e dos mercados consumidores (Varian, 1993). Além disso, a presença de empresas estrangeiras ou do capital externo na indústria nacional pode levar ao fortalecimento dos elos na cadeia produtiva (trade linkages) e do próprio setor (Julca-Briceño et al., 2010).

De modo geral, se reconhece que a presença de empresas estrangeiras e do capital externo na economia de um país pode gerar o incremento das importações e das exportações, aumentando o dinamismo do comércio externo. Ademais, as empresas transnacionais apresentam, em geral, elevados níveis de desenvolvimento tecnológico, característica que pode influenciar todo o setor, seu ambiente externo e, no limite, toda a economia de um país. O maior grau tecnológico incorporado por este tipo de empresa contribui para elevar as vendas externas (exportação), o valor agregado e a diversificação da pauta de exportações dos países onde estas empresas estão instaladas.

Neste sentido, a dinâmica econômica de um país está diretamente relacionada a sua organização industrial, ou seja, à composição de sua estrutura industrial. Pode-se dizer, em linhas gerais, que a organização industrial trata de como as indústrias operam, na tentativa de explicar como ocorrem as relações referentes ao comportamento dos preços e de seus recursos ao longo do tempo (Carlton, 1987). A forma como as empresas buscam sua produção potencial, a fim de realizar o seu crescimento estipulado pelos investimentos realizados (Guimarães, 1979), pode afetar toda a dinâmica setorial e da economia. Neste sentido, aspectos relacionados às fusões, aquisições, desregulamentação, globalização e a crescente competição são objetos de observações e investigações, emergindo daí uma nova visão para explicar a importância e o comportamento de uma organização industrial (Schmalensee, 1988).

North (1989) analisa a performance de uma determinada indústria considerando fatores como: interação contínua com instituições e organizações; investimento em novas habilidades e conhecimentos; percepção das habilidades na busca de obtenção dos melhores benefícios; modelos mentais dos agentes, dentre outros. O mesmo autor afirma também que a evolução das empresas e das indústrias ocorre quando é possível reduzir custos de transação devido às características como: aumento da mobilidade do capital, diminuição do custo da informação e a maior dispersão do risco.

A partir da análise da estrutura dos limites entre as empresas e os mercados é que se verifica a interação estratégica entre eles. A firma é um dos principais agentes que apresentam potencial para dinamizar o movimento da produção econômica capitalista, 
e suas inovações ocorrem a partir das interações, trocas de informações e de outros recursos (Campos e Paula, 2006). As estruturas, o comportamento e o desempenho das firmas estão relacionados ao ambiente institucional, envolvidos em uma dinâmica de retroalimentação e de interdependência entre eles. Além disso, Costa (2002) mostra que o desempenho competitivo das firmas industriais deve ser avaliado tanto pelos benefícios existentes em distritos industriais como também a partir do padrão de competição ao qual a indústria está vinculada. A competição pode ser caracterizada a partir de economias de mercado, que, segundo Kupfer e Hasenclever (2002), correspondem à demanda de um grupo de produtos substitutos próximos entre si.

Segundo Moraes et al. (2010), tanto os investidores interessados no mercado interno quanto os interessados em ganhos de eficiência preferem regiões com perspectivas de crescimento econômico e de elevação dos índices de produtividade, verificados historicamente ou com base em projeções. Nesta perspectiva, o Brasil torna-se um provável potencial líder mundial na produção de bioenergia e agroenergia. Segundo Moraes et al. (2010, p. 1), “[...] o Brasil tem potencial para se tornar uma 'Arábia Saudita Verde' [...]", tanto por ter a matéria-prima em abundância, quanto por ter o domínio da tecnologia. No entanto, para que esta liderança seja efetivamente alcançada, é necessário o desenvolvimento de novas tecnologias e melhoria das já existentes e na infraestrutura do país.

Diante dessa perspectiva, o setor sucroenergético brasileiro começou a atrair Investimento Direto Estrangeiro (IDE). O IDE pode ingressar de diversas maneiras, tais como aquisição de ações de empresas instaladas no país, empréstimos externos, entre outras formas. A forma de ingresso mais importante a ser considerada neste estudo é a entrada a partir da compra ou aquisição de empresas, fusões de empresas nacionais com transnacionais e a instalação de novas empresas com capital externo. O ingresso de capital externo pode alterar a dinâmica econômica de um setor, região ou país, dependendo de sua escala. O resultado prático dessa visão é a constituição de empresas estrangeiras ou transnacionais no setor sucroenergético brasileiro.

A presença de transnacionais pode levar ao fortalecimento dos elos na cadeia produtiva (trade linkages) em âmbito regional, nacional ou global. Outro aspecto positivo relacionado à entrada de empresas transnacionais é que, em geral, elas apresentam em seus processos e produtos níveis elevados de desenvolvimento tecnológico. Assim, as exportações podem contribuir para elevar seu valor agregado e a diversificação da pauta de exportações dos países. As empresas transnacionais também podem contribuir para o aperfeiçoamento das práticas de governança e gestão corporativa, além de estimular o surgimento de spillovers (Gregory e Oliveira, 2005). No entanto, a entrada do capital externo pode levar à concentração produtiva e tecnológica, alterando profundamente a estrutura e a dinâmica do mercado. 


\section{CARACTERIZAÇÃO DA ESTRUTURA PRODUTIVA DO SETOR SUCROENERGÉTICO BRASILEIRO}

O Brasil tem tradição secular no cultivo e processamento de cana-de-açúcar para a produção de açúcar. No início dessa atividade, o sistema de produção que se consolidou no país, especificamente na região Nordeste, baseava-se na monocultura extensiva, na grande propriedade, na mão de obra escrava e no elevado volume de capital (Garcia, 2007). O modelo atual ainda mantém a característica de monocultura extensiva e a necessidade de capital, isto é, prevalece a grande escala (Goldemberg e Lucon, 2007; Macedo, 2007), em função das economias de escala associadas a este modelo produtivo.

Contudo, o sistema atual baseia-se também no uso intensivo das terras e de novas tecnologias, com destaque para a biotecnologia e agroquímica renovável, como a sucroquímica. Mas o cultivo da cana-de-açúcar não está necessariamente em propriedade do usineiro como no passado; o cultivo está distribuído em um grande número de pequenas e médias propriedades rurais, que, em sua maioria, são arrendadas pela usina. Na safra 2011/2012, a participação no fornecimento de cana-de-açúcar pelos fornecedores externos alcançou 40,6\% do total (Mapa, 2013). Segundo Macedo (2007, p. 158), o processo adotado pelo setor sucroenergético brasileiro "exigiu extenso desenvolvimento tecnológico (geração, importação, adaptação e transferência de tecnologias) na produção agrícola e industrial e na logística”.

No país, o uso do etanol como combustível foi estimulado pela crise que abateu o setor açucareiro ainda no início do século XX, paralelo à crise de 1929, que abalou a economia capitalista. O governo brasileiro, a partir do Decreto ${ }^{\circ}$ 19.717, de 1931, tornou obrigatória a mistura de etanol à gasolina importada, na proporção mínima de 5\% (Pamplona, 1984). Esse ato foi o primeiro passo para a consolidação de um importante setor na economia brasileira, que posteriormente se mostrará como uma alternativa aos efeitos nocivos do uso dos combustíveis fósseis ao meio ambiente.

Entretanto, o grande e verdadeiro impulso ao setor sucroenergético brasileiro foi dado a partir do lançamento do Proálcool (Programa Nacional do Álcool), em 1975. O Proálcool estimulou não apenas a produção, mas o desenvolvimento tecnológico, com focos diferentes em suas várias fases (Leal, 2010; Neves e Cojenero, 2010). Todavia, a severa crise fiscal que abateu o Estado brasileiro ainda na década de 1980 alterou os rumos do programa, em especial, no que se refere às ações do Estado. Neste sentido, vale destacar a afirmação de Pereira (2012, p. 50):

[...] o novo contexto mundial fez com que a década de 1980 terminasse por enxugar os recursos destinados ao programa, resultando em uma mudança de paradigma, deixando de ser subvencionado pelo Estado e passando a concorrer numa estrutura aberta, o que imputava a busca por produtividade, ganhos de escala, escopo, entre outras medidas. Esse novo período ficou marcado pela introdução de tecnologias e 
inovações de processo e produtos, resultando no paradigma tecnológico que até hoje existe no setor.

Ainda, conforme destaca Pereira (2012), a partir de 1990, com a imposição de políticas macroeconômicas pelo governo brasileiro para recuperar a sua estabilidade econômica, o setor sucroenergético sofreu uma drástica redução dos subsídios fiscais e creditícios, abrindo espaço para a competição e o início do processo de enxugamento do setor. Acrescenta-se o fato de que ao longo da década de 1990 os preços do barril de petróleo mantiveram-se relativamente baixos quando comparados aos níveis verificados nas décadas de 1970/1980 (Garcia, 2007).

A partir do novo contexto, em função do elevado volume de resíduos gerados pela produção de etanol e açúcar, e estimulado pela discussão sobre a adoção de processos mais eficientes em termos econômicos, sociais e ambientais, o setor passou a integrar nas unidades produtoras centrais termoelétricas movidas a bagaço de cana-de-açúcar. Em outubro de 2010, a capacidade total instalada no Brasil para geração de energia termoelétrica da queima do bagaço era de 6 mil megawatts distribuídos em 313 usinas, representando 5\% da geração de energia elétrica no país (Conab, 2011). Assim, no período recente, essas unidades termoelétricas integradas, localizadas principalmente no estado de São Paulo, comercializam o excedente gerado de energia elétrica no mercado nacional (Goldemberg e Lucon, 2007), reforçando o parque energético nacional.

As usinas de etanol, no Brasil, tradicionalmente estavam concentradas na Zona da Mata da região Nordeste e no interior do estado de São Paulo. No período recente verifica-se um deslocamento dessa indústria para o norte do estado do Paraná e, mais recentemente, uma forte expansão para o Cerrado brasileiro, com destaque para os estados da região Centro-Oeste. O estudo do CGEE (2009) destaca que as áreas de cultivo da cana-de-açúcar localizam-se em um raio de aproximadamente $25 \mathrm{~km}$ das usinas, em razão dos custos de transporte. Desse modo, o deslocamento da produção de cana-de-açúcar traz consigo a sua estrutura industrial.

Segundo a Conab (2012a), o setor sucroenergético brasileiro era composto por 400 usinas na safra 2009/2010, distribuídas em 22 estados (Figura 1), ao passo que na safra 2007/2008 eram 343 unidades (Conab, 2008), o que representa um aumento de $16 \%$. No entanto, estima-se que o setor tenha em torno de 430 unidades em operação no país (Unica, 2011a). A produção nacional de etanol na safra 2009/2010 alcançou 25,7 milhões de $\mathrm{m}^{3}$, mas na safra 2011/2012 alcançou apenas 22,7 milhões de $\mathrm{m}^{3}, 11 \%$ menor, mas $18,8 \%$ maior em relação à anterior (ANP, 2012) ${ }^{3}$. O estado de São Paulo

3 Essa redução resultou de problemas climáticos que afetaram a produção de cana-de-açúcar, além do aumento na produção de açúcar em função do preço que estava mais vantajoso no mercado internacional quando comparado ao preço do etanol no mercado interno (ANP, 2012). 
concentra em média 42\% das usinas em operação, que responderam na safra 2011/2012 por $51 \%$ da produção nacional de etanol (MAPA, 2013).

Figura 1 - Distribuição Espacial das Unidades Produtivas (safra 2009/2010) e da Produção de Etanol (safra 2011/2012*) por Unidade Federativa
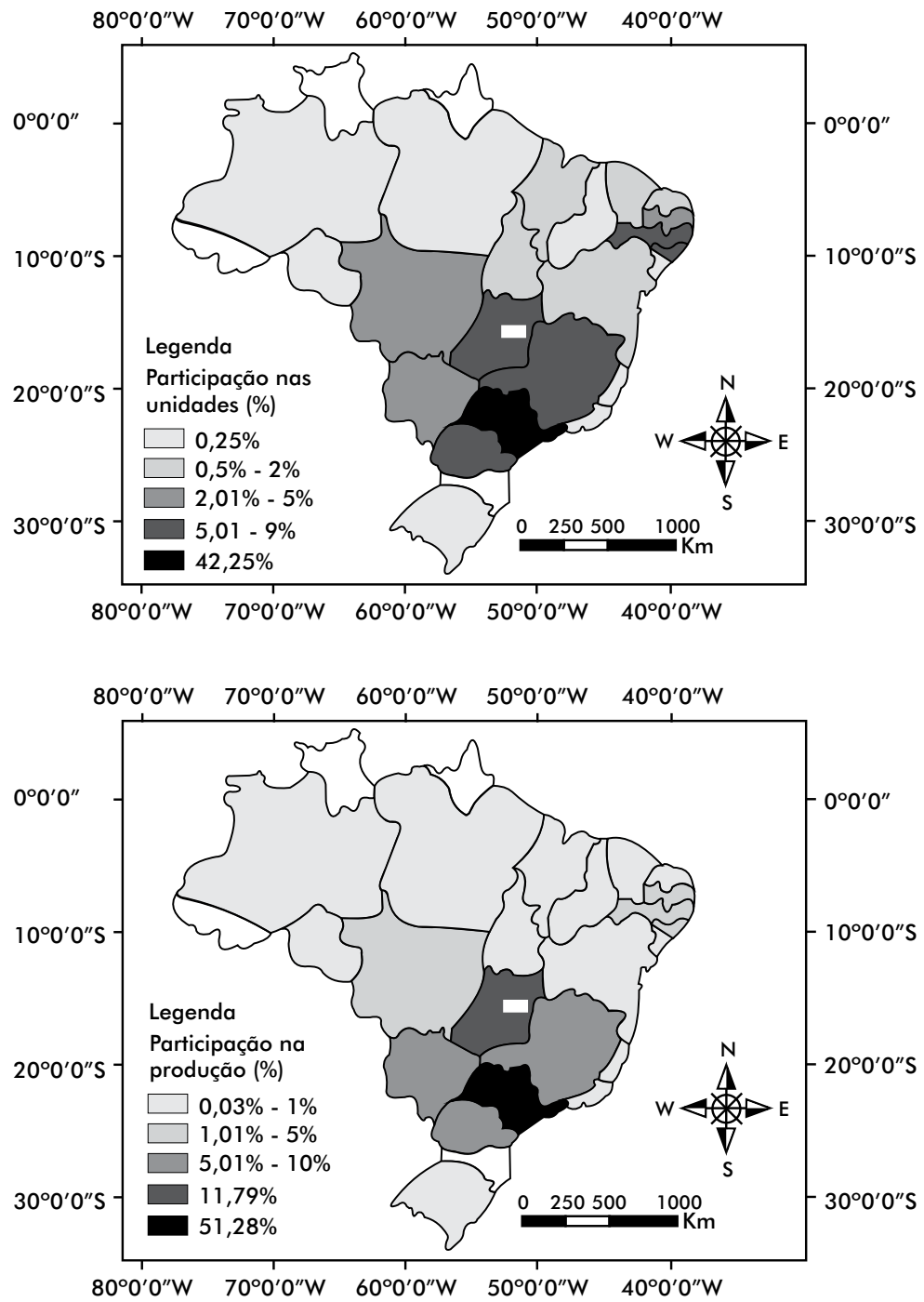

Nota: Dados apurados em 15/05/2012. As unidades federativas em branco não apresentam registro. Fonte: Elaboração própria com base em Conab (2012a). 
Estima-se que o setor envolva 70 mil produtores rurais em sua cadeia produtiva, gerando em torno de 1,2 milhão de empregos diretos e um Produto Interno Bruto Setorial da ordem de US\$ 48 bilhões, e responde em média por $20 \%$ da produção e das exportações mundiais de etanol (Unica, 2011a). Segundo CGEE (2009), estima-se que cerca de $65 \%$ da área de cultivo da cana-de-açúcar esteja em propriedade das usinas e $35 \%$ de produtores independentes.

O setor é caracterizado pelo grande número de unidades produtivas e empresas controladoras, o que significa uma relativa atomização da produção. $\mathrm{Na}$ safra 2006/2007, as 10 maiores empresas do setor sucroenergético do Centro-Sul responderam por 13\% da produção nacional de etanol (CGEE, 2009) (Tabela 1).

Tabela 1 - Principais produtores de etanol da Região Centro-Sul, ano safra 2006/2007

\begin{tabular}{lcc}
\hline Unidade & $\begin{array}{c}\text { Etanol } \\
\text { (milhões de litros) }\end{array}$ & $\begin{array}{c}\text { Moagem Total } \\
\text { (milhões de toneladas) }\end{array}$ \\
\hline Da Barra & 289,3 & 7,02 \\
São Martinho & 286,3 & 6,74 \\
Santa Elisa & 270,1 & 5,96 \\
Vale do Rosário & 230,6 & 5,49 \\
Itamarati & 230,0 & 5,08 \\
Da Pedra & 216,8 & 4,10 \\
Equipav & 214,0 & 4,43 \\
Catanduva & 212,4 & 3,91 \\
Moema & 198,3 & 4,41 \\
Colorado & 181,3 & 4,48 \\
Total & $\mathbf{2 . 3 2 9 , 1}$ & $\mathbf{5 1 , 6}$ \\
\% do total nacional & $\mathbf{1 3 , 0 \%}$ & $\mathbf{1 2 , 0 \%}$ \\
Total Nacional & $\mathbf{1 7 . 9 3 9 , 5}$ & $\mathbf{4 2 8 , 8 0}$ \\
\hline
\end{tabular}

Fonte: CGEE (2009, p. 96)

A estrutura industrial brasileira do setor sucroenergético abriga usinas com capacidade de moagem de cana-de-açúcar menores que um milhão de toneladas ao ano a aquelas com capacidade superior a cinco milhões de toneladas. Do total de usinas em operação na safra 2009/2010, apenas $8 \%$ tinham capacidade superior a 5 milhões de toneladas (ao todo eram 33 usinas na safra 2009/2010), 29 localizadas no estado de São Paulo e três no estado do Mato Grosso. As regiões Norte e Nordeste abrigavam predominantemente unidades com capacidade para processar até 1 milhão de toneladas, um total de 54 usinas. Destas, 31 usinas tinham capacidade maior que um milhão e menor que dois milhões, e apenas uma usina tinha capacidade entre três a quatro milhões de toneladas (Tabela 2). 
Tabela 2 - Distribuição das Unidades de Produção por Capacidade de Moagem de Cana-de-açúcar e por Estado Brasileiro, safra 2009/2010

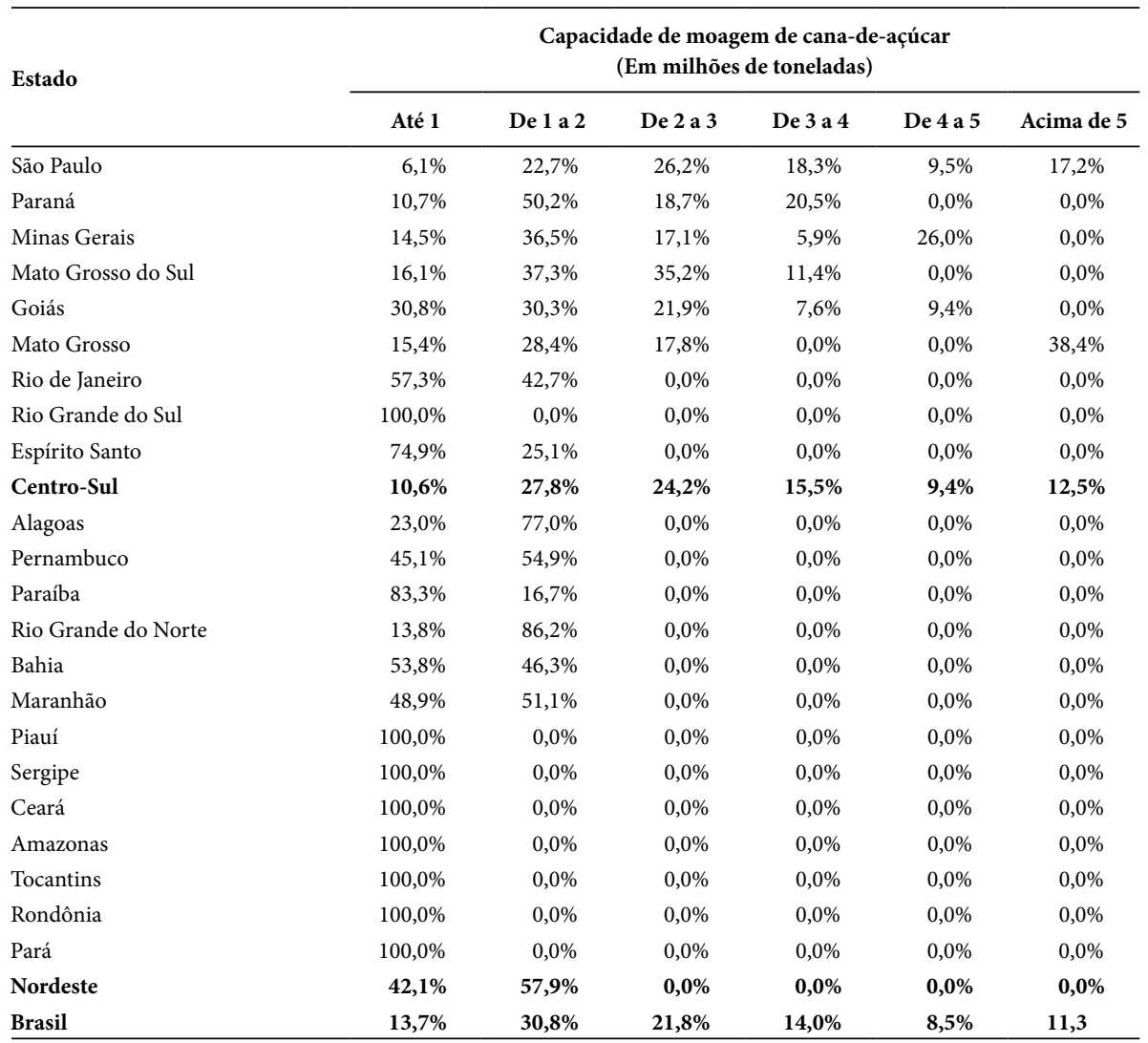

Fonte: Elaboração própria com base em dados de Conab (2012a).

Por fim, um aspecto interessante verificado pelo estudo da Conab (2012a) é a baixa utilização da capacidade de produção de etanol instalada. A média de utilização da capacidade de produção de etanol no Brasil na safra 2009/2010 alcançou apenas 53,9\%, ou seja, $46,1 \%$ de "capacidade ociosa". O estado brasileiro com a menor utilização da capacidade instalada na produção de etanol era Tocantins 5,6\%, e a maior utilização foi verificada no estado do Maranhão, que alcançou 86,9\%. O estado de São Paulo apresentou um uso de 55,7\% da capacidade instalada de produção de etanol, mas em relação ao uso da capacidade de moagem, esta alcançou 78\%. Esse cenário revela que há espaço para expansão da produção de etanol, mas esta depende da oferta de cana-de-açúcar.

As informações apresentadas nesta seção mostraram um breve panorama do setor sucroenergético brasileiro em termos de sua estrutura industrial, além de revelar a elevada concentração espacial e ociosidade da estrutura produtiva do setor. 


\section{A ENTRADA DAS TRANSNACIONAIS NO SETOR SUCROENERGÉTICO BRASILEIRO}

A presença do capital externo no setor sucroenergético brasileiro não é recente, embora tenha permanecido um pouco distante na década de 1990 e nos primeiros anos do século XXI. A relação entre o capital nacional e externo se estreitou a partir da proposta de internacionalização do uso do etanol como substituto parcial ou total à gasolina. A retomada dessa relação pode ser marcada pela entrada no país dos produtores europeus de açúcar, com destaque para os grupos franceses Tereos e Louis Dreyfus. Essa nova dinâmica atraiu a atenção também das grandes tradings internacionais e de grupos asiáticos. Estima-se que mais 20 conglomerados internacionais comandem ou tenham participação acionária em empresas do setor sucroenergético brasileiro, excluso as três empresas com capital aberto na BM\&F Bovespa (Siamig, 2009), sendo elas: Cosan S.A., Indústria e Comércio, Açúcar Guarani S.A. e São Martinho S.A. (Caixe e Baccarin, 2009).

No Quadro 1 é apresentado um levantamento dos grupos estrangeiros que realizaram investimentos no setor sucroenergético brasileiro a partir de aquisições (brownfields) ou de novas plantas industriais (greenfield) entre 2000 e 2010. Optou-se por apresentar os dados após 2000 por considerar ser este o período em que se inicia a efetiva entrada mais acentuada de grupos estrangeiros no setor sucroenergético brasileiro.

Os dados do Quadro 1 indicam que a principal opção de entrada de capital estrangeiro foi pelo controle acionário da empresa a partir de aquisições. Este tipo de ingresso pode ser derivado da percepção de que com o controle da empresa os grupos estrangeiros teriam maior autonomia em suas decisões produtivas e de comercialização. Outro aspecto verificado é que o estado de São Paulo apresenta o maior número de empresas adquiridas, evidentemente porque este estado concentra o maior número de empresas consolidadas.

Cabe destacar ainda que entre 2002 e 2003 não há registro de transações internacionais no setor. Provavelmente essa ausência estaria relacionada ao processo de ajustamento pós-crise internacional de 2001, em que o setor ainda vivenciava os efeitos da crise interna iniciada no fim da década de 1980, com a queda do preço do barril de petróleo e a estagnação do consumo de etanol no Brasil em função da redução da produção de veículos movidos a etanol (Garcia, 2007). Ressalta-se, contudo, que neste período ocorreram aquisições no mercado nacional comandadas, principalmente, pelo Grupo Cosan, ou seja, uma reorganização interna da estrutura industrial.

Uma característica comum encontrada nas estratégias das grandes unidades é o aprofundamento na especialização da produção de açúcar e etanol, a partir da intensa automatização e padronização do sistema produtivo (Watanabe, 2001). Esse processo está tanto na fase industrial como também na fase agrícola, caracterizado basicamente 
pela intensa mecanização do cultivo da cana-de-açúcar, exigida pelo compromisso assumido do setor com o poder público, acompanhado pela terceirização de parcelas das atividades agrícolas e industriais, assim como a criação de programas de qualidade em todo o processo (Moraes e Shikida, 2002).

\section{Quadro 1 - Grupos estrangeiros e investimentos realizados no Brasil, 2000-2010}

\begin{tabular}{|c|c|c|c|}
\hline Ano & Comprador & Empresa adquirida/Estado & Transação \\
\hline 2000 & FBA & Ipaussu (SP) & $\mathrm{Nd}$ \\
\hline 2000 & Coinbra/Louis Dreyfus Dreyfus (LDF) & Usina Cresciumal (SP) & A \\
\hline 2000 & Glencore & Refinadora Catarinense/Usati (SC) & A \\
\hline 2001 & FBA & Univalen/Ganabara Agro-Industrial (SP) & A \\
\hline 2001 & Béghin-Say & Açúcar Guarani (SP) & A \\
\hline 2001 & Coimbra-Dreyfus & Usina Luciânia (MG) & A \\
\hline 2001 & FBA & Usina Santo Antônio (SP) & Arr \\
\hline 2004 & Louis Dreyfus Commodities (LDF) & São Carlos Usina Açucareira de Jabotical (SP) & A \\
\hline 2004 & Tereos & Açúcar Guarani (SP) & A \\
\hline 2006 & Louis Dreyfus Commodities (LDF) & Tavares de Melo (PB) & A \\
\hline 2006 & $\begin{array}{l}\text { Adecoagro (Fundo de Investimento } \\
\text { - George Soros) }\end{array}$ & Monte Alegre (MG) & A \\
\hline 2006 & Evergreen & $\begin{array}{l}\text { Cristal Destilaria Autônoma de Álcool } \\
\text { (Cridasa) (ES) }\end{array}$ & A \\
\hline 2006 & Cargill & Cevasa (SP) & A \\
\hline $2006 / 07$ & InfinityBio-Energy & $\begin{array}{l}\text { Cridasa (ES), Disa (ES), Alcana (MG), Paraiso } \\
\text { (SP) e Usinavi (MS), Ibirálcool (BA), Cepar } \\
(\mathrm{MG}) \text { e Agromar (RN) }\end{array}$ & A \\
\hline 2007 & ETH Bionergia & Destilaria Alcídia (SP) & A \\
\hline 2007 & Sojitz Corporation & ETH Bionergia (SP/GO) & $\mathrm{F}$ \\
\hline 2007 & Clean Energy Brazil (CEB) & Alcoolvale (MS) & $\mathrm{F}$ \\
\hline 2007 & Abengoa & Grupo Dedini Agro Açúcar e Álcool (SP) & A \\
\hline 2008 & $\mathrm{BP}$ & Tropical Bioenergia (GO) & $\mathrm{F}$ \\
\hline 2008 & ETH Bioenergia & Usina Eldorado (MS) & A \\
\hline 2009 & Tereos & Açúcar Guarani (SP) & A \\
\hline 2009 & ETH Bioenergia & Brenco (GO) & $\mathrm{F}$ \\
\hline 2009 & Louis Dreyfus Commodities (LDF) & Usina Santelisa Vale (SP) & JV \\
\hline 2009 & ShreeRenukaSugarsLtd. & Vale do Ivai (PR) & A \\
\hline 2009 & Clarion & Manacá (Nd) & $\mathrm{A}$ \\
\hline $2009 / 10$ & Bunge Ltd. & Grupo Moema (SP) & A \\
\hline 2010 & ShreeRenukaSugarsLtd. & Equipav. Açúcar e Álcool & $\mathrm{A}$ \\
\hline 2010 & Açúcar Guarani & Usina Vertente (SP) & A \\
\hline
\end{tabular}

Nota: Nd - Não disponível; A - aquisição; JV - Joint venture; F - Fusões; Arr - Arrendamento.

Fonte: Adaptado de Siqueira e Castro Júnior (2010). 
Algumas empresas preferiram seguir a trajetória da diferenciação dos produtos, exigindo maior controle do processo de qualidade e de fabricação ${ }^{4}$. As empresas que adotaram essa estratégia estenderam suas atividades para a destilaria, incorporando ao processo a cogeração de energia termoelétrica, fornecimento de garapa para produção de ciclamato monossódico ou para atuar em outras atividades. Outras empresas optaram pela fusão baseada na sinergia e pela aquisição para a expansão ou para a entrada em novas regiões do Brasil $^{5}$ (Moraes e Shikida, 2002).

Neste novo contexto, verifica-se também que os investimentos realizados no setor sucroenergético, em especial os investimentos estrangeiros, têm sido direcionados para ampliação da estrutura produtiva, aumento da produtividade, melhoria da logística para escoamento e estocagem ou aquisição acionária. Entre 2008 e 2012 estima-se que foram investidos US\$ 23 bilhões no setor sucroenergético brasileiro, distribuídos em 76 projetos de construção de novas usinas, além de mais US\$ 10 bilhões na produção de cana-de-açúcar (Neves e Cojenero, 2010). No entanto, a crise econômico-financeira iniciada em 2007/2008 e o relativo "congelamento" dos preços da gasolina no Brasil representam um grande desafio para que esse cenário de expansão que vinha se delineando desde 2003/2004 seja mantido.

Os fatores que podem ter motivado a entrada de capital externo neste setor são as estimativas e perspectivas otimistas de consolidação de um mercado internacional para o etanol, com perspectivas de expansão da demanda caso a rota tecnológica de produção e uso de combustíveis renováveis seja adotada mundialmente (MAPA, 2013). Outro fator é a competitividade que o etanol produzido a partir de cana-de-açúcar no Brasil tem em relação às demais matérias-primas utilizadas em outros países. Estas vantagens garantem um produto competitivo e atrativo para a sua comercialização no mercado internacional.

De acordo com Castro e Dantas (2009, p. 3):

A entrada de grandes players nacionais e internacionais no setor sucroenergético permite que a expansão do setor ocorra com base na construção do que se pode denominar "fábricas de energia", apresentando maior escala de produção, buscando e viabilizando a obtenção de significativas economias de escala. A possibilidade de explorar essas economias de escala é relevante para a promoção de investimentos na

4 Um exemplo desta mudança quanto à opção e diversificação dos produtos do setor sucroenergético pode ser verificado no estudo de Lima et al. (2012).

5 Para aprofundar esta discussão de estratégias empresariais das empresas do setor sucroenergético ver Lima e Ramos (2009). 
geração de eletricidade pela redução nos custos do investimento e pelo poder de barganha que esta maior escala concede ao grupo econômico no momento de negociar a comercialização da sua energia.

A nova configuração estrutural do setor sucroenergético brasileiro, caracterizada pela exacerbação da escala produtiva, acompanhada pela diversificação dos produtos, com destaque para cogeração e o uso dos insumos gerados pela cana-de-açúcar em outros produtos, como o "bioplástico", tem pressionado a necessidade de profissionalização das empresas. Esta necessidade se tornou ainda mais urgente devido à crise mundial de 2008, que afetou fortemente o equilíbrio econômico-financeiro deste setor, em função do alto grau de endividamento e da dependência dos fluxos de capitais externos e de grandes investidores estrangeiros (Pinto, 2011). Esta crise tem provocado uma série de aquisições e fusões que tem resultado em um novo mapa de produção e controle das empresas no Brasil.

Destaca-se que ainda que a entrada de capital estrangeiro foi incentivada pela estrutura institucional do setor sucroenergético, consolidada a partir da desregulamentação realizada nos anos de 1990. A desregulamentação favoreceu as expectativas quanto às oportunidades de lucratividade com menores riscos, e as decisões produtivas devidas à saída do Estado, principalmente em relação aos aspectos de licença para abertura de novas empresas e as cotas de exportações de açúcar (Watanabe, 2001).

A entrada de capital estrangeiro a partir das aquisições ou fusões tem sido tão forte que pode ter afetado negativamente, inclusive, a construção de novas usinas. Os números do setor apontam uma queda significativa no número de usinas novas para inauguração no país. Na safra de 2008/2009 foram construídas 34 usinas, na safra seguinte o número se reduziu para 19, depois 10, e na safra 2011/2012 não há registro de que novas unidades industriais foram iniciadas no país, mesmo com as boas perspectivas de expansão e com o aumento dos preços pagos pelo etanol (Carvalho, 2012). É evidente que o cenário de crise internacional e do próprio setor afetou as decisões dos agentes na implantação de novas unidades produtivas, mas esse cenário não afetou drasticamente a entrada de capital externo, ou seja, capital existe, mas este capital está sendo alocado na aquisição e fusão. Esta redução do ritmo de crescimento do setor afetou o ritmo de expansão e renovação das lavouras de cana-de-açúcar no país, que registrou um índice de evolução de apenas 2\% para a safra 2012/2013. Segundo a Conab (2012b, p. 4), "A falta de investimento em novas unidades, ou mesmo na ampliação da capacidade de processamento das já existentes, bem como a renovação de áreas já cultivadas dificultam maior crescimento".

Estima-se que a participação do capital estrangeiro no setor sucroenergético nacional tenha atingido 25\% em 2011, ao passo que era de apenas 6\% em 2006 (Carvalho, 
2012). Essa estimativa é reforçada por Nastari (2010), que identificou uma participação relativa das empresas controladas pelo capital estrangeiro na capacidade total de moagem de 25,5\% na safra 2010/2011 ante $11,9 \%$ na safra 2007/2008. Destaca-se ainda que o crescimento da participação do capital estrangeiro concentra-se em aquisições de empresas instaladas, o que não modifica a estrutura industrial do setor em um primeiro momento, embora afete sua dinâmica. Espera-se que, após a aquisição, os novos proprietários promovam a modernização do parque produtivo e o aumento da capacidade instalada.

Outro fator a ser destacado é que o país necessita aumentar sua oferta de etanol para conseguir consolidar este produto no mercado nacional e internacional com uma oferta estável capaz de atender à demanda externa crescente, estimada em 205 bilhões de litros em 2025 (CGEE, 2009). Desse modo, o aumento da oferta dependerá de novos investimentos na melhoria da capacidade produtiva e gerencial das empresas instaladas, pois há indicação de que várias usinas operam com capacidade ociosa - a média da capacidade de uso das usinas de etanol no Brasil é de apenas 53,9\%, de acordo com dados da Conab (2012a) -, seja pela construção de novas unidades industriais, além da ampliação e renovação das áreas de cultivo.

No entanto, salienta-se que existem alguns entraves para a continuidade do processo de investimentos pelos capitais internacionais a partir da aquisição ou fusão no setor. Segundo Siqueira e Castro Júnior (2010, p. 22):

[...] o ritmo de fusões e aquisições no setor de cana deve se manter, mas há obstáculos, como a composição societária das empresas, muitas delas com forte tradição familiar, e outras com problemas contábeis, visto que poucas usinas de cana-de-açúcar fizeram a abertura de seu capital.

A construção de novas unidades industriais no país poderá alterar a configuração espacial e da estrutura industrial do setor. Os novos investimentos nos demais estados brasileiros contribuem para diminuir a participação relativa do estado de São Paulo, que responde por mais da metade da produção de etanol, bem como equilibrar a oferta nas diferentes regiões. Conforme dados apresentados no mapa 1, a dinâmica espacial do setor indica que os principais estados que têm recebido estes novos investimentos são os estados de Goiás, Mato Grosso do Sul e Minas Gerais.

Os dados da Conab (2012b) indicam que a produção estimada de etanol para a safra 2012/2013 será de 23,6 bilhões de litros, representará um aumento de $4 \%$ em relação à safra 2011/2012 (22,7 bilhões de litros). Esse desequilíbrio entre oferta e demanda gera instabilidade no mercado, que é prejudicado pelos picos de alta do preço e pela queda na rentabilidade do etanol frente ao açúcar que tem apresentado altos 
preços no mercado internacional. Por isso, novos investimentos neste setor são tão importantes para a criação de um mercado de etanol estável e com garantia de oferta até mesmo no período de entressafra, como forma de inserir-se no mercado internacional como um dos exportadores mais importantes e consolidar o etanol como uma alternativa viável ao combustível fóssil.

Desta forma, os investimentos estrangeiros representam uma importante fonte de alavancagem para o setor, o qual tem registrado ao longo de sua história uma relativa instabilidade (Garcia, 2007). Nesse sentido, o Governo brasileiro tem favorecido em vários momentos a realização de financiamentos para o setor sucroenergético. Neste aspecto, merece destaque o lançamento do plano conjunto envolvendo o BNDES (Banco Nacional de Desenvolvimento Econômico e Social) e a Finep (Financiadora de Estudos e Projetos) para apoiar a inovação no setor sucroenergético em 2011, o Plano de Apoio à Inovação Tecnológica Industrial dos Setores Sucroenergético e Sucroquímico (PAISS) (Nyko et al., 2013; Finep, 2013; BNDES, 2015). O plano é composto por três linhas temáticas: I) bioetanol de $2^{\text {a }}$ geração ou celulósico $(2 \mathrm{G})$; II) novos produtos de cana-de-açúcar; e III) gaseificação. Além disso, o volume estimado de recursos disponíveis para o período 2011-2014 era de R\$ 1 bilhão. Embora o volume de recursos seja considerável, os projetos têm um limite máximo de financiamento, $\mathrm{R} \$ 10$ milhões.

A internacionalização do setor sucroenergético brasileiro pode ter influenciado a criação do PAISS, porque havia um claro movimento no cenário internacional para o desenvolvimento tecnológico de biocombustíveis celulósicos ou de segunda geração (2G), e o Brasil ainda não estava inserido nesta dinâmica (Nyko et al., 2010). Além disso, o setor privado nacional tinha baixa participação no desenvolvimento do etanol $2 \mathrm{G}$ (Nyko et al., 2013). Assim, a entrada do capital externo no país pode ter estimulado a inserção na agenda política e do setor o desenvolvimento do etanol $2 \mathrm{G}$ como estratégia para manter ou mesmo elevar sua competitividade no mercado nacional e internacional. Segundo o estudo de Nyko et al. (2013), antes do lançamento do PAISS, a carteira conjunta (BNDES-Finep) voltada aos projetos de etanol $2 \mathrm{G}$ era de R\$ $70 \mathrm{mi}-$ lhões, e em 2013 já alcançava R\$ 1,5 bilhões, embora a carteira do PAISS tenha alcançado R \$ 3,3 bilhões em 2013. Esse aumento no volume do financiamento de projetos vinculados ao setor sucroenergético e sucroquímico revela parte dos resultados do PAISS do ingresso de capital externo.

O PAISS contribuiu para a atração de novos agentes para o nascente setor do etanol 2G, inclusive com a criação de subsidiárias brasileiras de empresas transnacionais, e realização de parcerias entre empresas e universidades (Nyko et al., 2013). Desse modo, a entrada do capital externo pode ter reforçado e até mesmo acelerado o desenvolvimento tecnológico no país no setor sucroenergético, o que tem incluído os setores agrícola, industrial e acadêmico - parcerias com universidades e institutos de pes- 
quisa. Além disso, o PAISS selecionou Planos de Negócio (PN) de um total de 25 empresas, das quais 19 eram transnacionais (Quadro 2), reforçando a importância do capital externo para impulsionar os investimentos em Pesquisa e Desenvolvimento (P\&D) no Brasil. Os PN do total de empresas estavam distribuídos em: sete em etanol 2G; 12 em novos produtos; cinco em etanol 2G e novos produtos; um em etanol $2 \mathrm{G} \mathrm{e}$ gaseificação (BNDES, 2015).

\section{Quadro 2 - Empresas com Planos de Negócio selecionados pelo PAISS por linha temática e por origem do capital}

\begin{tabular}{|c|c|c|c|c|}
\hline Razão Social & Linha I & Linha II & Linha III & Transnacional \\
\hline Abengoa Bioenergia Agroindustrial Ltda. & $\mathrm{X}$ & & & $\mathrm{X}$ \\
\hline Agacê Sucroquímica Ltda. & & $\mathrm{X}$ & & \\
\hline Amyris Pesquisa e Desenvolvimento de Biocombustíveis & & $\mathrm{X}$ & & $\mathrm{X}$ \\
\hline Baraúna Comércio e Indústria Ltda. & & $\mathrm{X}$ & & \\
\hline BioFlex Agroindustrial Ltda. & $\mathrm{X}$ & & & \\
\hline $\mathrm{BiOMM} \mathrm{S/A}$ & $\mathrm{X}$ & & & $\mathrm{X}$ \\
\hline Bunge Açúcar e Bioenergia Ltda. & & $\mathrm{X}$ & & $\mathrm{X}$ \\
\hline Butamax Biocombustíveis Avançados & & $\mathrm{X}$ & & $\mathrm{X}$ \\
\hline CTC - Centro de Tecnologia Canavieira S.A. & $\mathrm{X}$ & $\mathrm{X}$ & & \\
\hline Dow Brasil S/A & $\mathrm{X}$ & $\mathrm{X}$ & & $\mathrm{X}$ \\
\hline DSM South América Ltda. & $\mathrm{X}$ & $\mathrm{X}$ & & $\mathrm{X}$ \\
\hline Du Pont do Brasil S/A & & $\mathrm{X}$ & & $\mathrm{X}$ \\
\hline Eli Lilly do Brasil Ltda. & $\mathrm{X}$ & & & $\mathrm{X}$ \\
\hline ETH Bioenergia S.A. & $\mathrm{X}$ & $\mathrm{X}$ & & $\mathrm{X}$ \\
\hline Ideom Tecnologia Ltda. & & $\mathrm{X}$ & & $\mathrm{X}$ \\
\hline Kemira Chemicals Brasil Ltda. & & $\mathrm{X}$ & & $\mathrm{X}$ \\
\hline LS9 Brasil Biotecnologia Ltda. & & $\mathrm{X}$ & & \\
\hline Mascoma Brasil & $\mathrm{X}$ & & & $\mathrm{X}$ \\
\hline Methanum Engenharia Ambiental Ltda. & & $\mathrm{X}$ & & \\
\hline Metso Paper South America Ltda. & $\mathrm{X}$ & & & $\mathrm{X}$ \\
\hline Novozymes Latin America Ltda. & $\mathrm{X}$ & & & $\mathrm{X}$ \\
\hline Petrobras S/A & $\mathrm{X}$ & & $\mathrm{X}$ & $\mathrm{X}$ \\
\hline PHB Industrial S/A & & $\mathrm{X}$ & & $\mathrm{X}$ \\
\hline Solazyme Brasil Óleos Renováveis e Bioprodutos Ltda & & $\mathrm{X}$ & & $\mathrm{X}$ \\
\hline VTT Brasil - Pesquisa e Desenvolvimento Ltda. & $\mathrm{X}$ & $X$ & & $\mathrm{X}$ \\
\hline
\end{tabular}

Fonte: Elaboração própria com base em dados de BNDES (2015).

Nesta seção foi possível verificar o ingresso de capital externo no setor sucroenergético brasileiro, e alguns de seus desdobramentos. Desse modo, na próxima seção são discutidas as considerações gerais deste estudo, focando nas perspectivas e nos desafios para o setor sucroenergético dentro desta nova configuração, com a entrada de capital estrangeiro, e as dinâmicas originárias desta movimentação. 


\section{CONSIDERAÇÕES GERAIS: PERSPECTIVAS E DESAFIOS DO “NOVO" SETOR SUCROENERGÉTICO BRASILEIRO}

A entrada de capital externo no setor sucroalcooleiro brasileiro foi estimulada pela retomada do consumo do etanol no mercado interno a partir do lançamento do veículo bicombustível, pela possibilidade de o etanol se consolidar como uma alternativa viável ao uso do combustível fóssil no mercado internacional, pelo elevado patamar do preço do barril de petróleo e pela intensificação do debate sobre os efeitos das mudanças climáticas. Além disso, no caso brasileiro, cabe destacar o papel da desregulamentação do setor sucroenergético incentivado pelas expectativas de maior transparência e movimentação dos capitais.

Os investimentos externos têm se concentrado na aquisição de empresas antigas, mas uma parcela menor do capital externo tem sido direcionada para a construção de novas plantas industriais. A entrada do capital externo alterou a dinâmica do setor, em especial nas atividades de ciência e tecnologia a partir das parcerias realizadas por empresas como a Monsanto, Basf e Bayer com instituições de pesquisa nacional (Quadro 1), mas também pelos investimentos no desenvolvimento do etanol 2G (Quadro 2). Ademais, o capital externo proporcionou a internacionalização do setor sucroenergético brasileiro, uma vez que este controla em torno de $25 \%$ da capacidade total de moagem.

Os investimentos em novas plantas industriais têm se concentrado nas regiões de expansão da cana-de-açúcar, especificamente no Centro-Oeste, Minas Gerais e na região Sudeste. Ressalta-se que o mercado interno tem uma demanda maior que a oferta que tem sido realizada pelo setor, o que sinaliza a necessidade de aumentar os ritmos de investimentos em novas plantas industriais, na melhoria da eficiência produtiva das plantas antigas, e claro, no desenvolvimento tecnológico de novas variedades de cultivares, novos combustíveis como o etanol $2 \mathrm{G}$ e mesmo $3 \mathrm{G}$, mesmo em novas áreas como a química renovável.

Contudo, apesar da entrada do capital externo e do dinamismo vivenciado desde 2003/2004, o setor sucroenergético ingressou em uma nova e severa crise, que tem como pano de fundo um período relativamente extenso com níveis de preços abaixo do necessário para remunerar o investimento, embora a demanda estivesse aquecida, elevado endividamento das empresas e, em determinados casos, problemas gerenciais, com destaque para empresas controladas pelo capital externo, que não conheciam plenamente $\mathrm{o}$ ambiente institucional brasileiro.

Por um lado, esse pano de fundo contribuiu para uma drástica redução no nível de investimentos na renovação dos canaviais, refletindo na gestão das unidades produtivas do setor industrial e na significativa queda de produtividade agrícola e industrial. Neste sentido, a entrada do capital externo pode ter contribuído para o aprofunda- 
mento da crise setorial, uma vez que os recursos não foram direcionados para os pontos críticos da cadeia produtiva, além da falta de conhecimento e informação da dinâmica setorial e do mercado por parte das empresas controladoras. Desse modo, a falta de experiência dos grupos externos controladores das empresas adquiridas na dinâmica do setor, as diferenças culturais, institucionais, entre outros fatores, podem ter contribuído para o aprofundamento da crise.

Por outro lado, estimativas realizadas pelo CGEE (2009) apontam que as terras aptas para o cultivo de cana-de-açúcar, respeitando as reservas ambientais, parques nacionais, áreas indígenas, áreas militares e urbanas e áreas com algum tipo de restrição, somam 106,6 milhões de hectares. O estudo destaca ainda que, desse total, cerca de 80,2 milhões de hectares estariam disponíveis e aptos para o cultivo da cana-de-açúcar em 2025, excluídas as áreas utilizadas pelas demais culturas. Desse modo, espaço para a expansão do cultivo existe, mas os empresários ainda permanecem reticentes em relação à realização de novos investimentos, especialmente em função das incertezas presentes no mercado, em especial, a respeito do preço da gasolina.

Apesar das perspectivas de expansão do consumo de etanol no mercado interno e externo, da disponibilidade de terras para expansão do cultivo, das tendências de elevação do preço do barril de petróleo e das restrições impostas pelos efeitos do aquecimento global, o setor sucroenergético ainda vivencia um período de incertezas quanto ao retorno dos investimentos. Embora o Governo brasileiro tenha lançado mão de novos incentivos para estimular a retomada dos investimentos, o setor ainda dá sinais de que não realizará os investimentos necessários para reverter o cenário de crise, em função do elevado endividamento das empresas - em particular das empresas nacionais -, e, no caso das empresas controladas pelo capital externo, em função da insegurança de elevar o aporte de capital, não sendo possível ter a certeza de obter o retorno esperado. Neste sentido, a presença do capital externo conseguirá alterar o paradigma tecnológico vigente no setor?

Um resultado dessa nova dinâmica é visível: os investimentos em novas tecnologias vinculadas ao uso da cana-de-açúcar apresentam aceleração no período recente, com destaque para o PAISS, mas esse impulso será suficiente para a retomada do setor sucroenergético brasileiro?

\section{REFERÊNCIAS}

AGÊNCIA NACIONAL DO PETRÓLEO, GÁS NATURAL E BIOCOMBUSTÍVEIS (ANP). Anuário estatístico brasileiro do petróleo, gás natural e biocombustíveis: 2012. [On-line] ANP, 2012. Disponível em: <www.anp.gov.br>. Acesso em: 22 fev. 2013 
BANCO NACIONAL DE DESENVOLVIMENTO ECONÔMICO E SOCIAL (BNDES). Plano Conjunto BNDES-Finep de Apoio à Inovação Tecnológica Industrial dos Setores Sucroenergético e Sucroquímico - PAISS. Disponível em: <http://goo.gl/3IwYCt>. Acesso em: 17 jun. 2015.

CAIXE, D. F.; BACCARIN, J. G. Empresas sucroalcooleiras de capital aberto: avaliação da estrutura de controle e de indicadores financeiros. In: Congresso de Iniciação Científica UNESP, 21, São José do Rio Preto, SP, 2009. Anais... S. J. do Rio Preto: UNESP, 2009. v. 1. p. 9783-9791. Disponível em: <http://prope.unesp.br/xxi_cic /99_33501357818.pdf>. Acesso em: 28 fev. 2013.

CAMPOS, A. C; PAULA, N. M. Novas formas de organização industrial e o conceito de firma: uma abordagem neo-schumpeteriana. Ensaios FEE, Porto Alegre, v. 27, n. 1, p. 31-56, mai. 2006.

CARLTON, D. W. The Theory and the facts of how markets clear: is industrial organization valuable for understanding macroeconomics? NBER Working Papers, n. 2178, 1987. Disponível em: <http://www.nber.org/papers/w2178>. Acesso em: 20 nov. 2012.

CASTRO, N. J. DE; DANTAS, G. de A. Fusões e aquisições no setor sucroenergético e a importância da escala de geração. Texto para Discussão do Setor Elétrico, GEE/IE-UFRJ, n. 14, nov. 2009.

CARRIQUIRY, M. A.; DU, X.; TIMILSINA, G. R. Second generation biofuels: Economics and policies. Energy Policy, v. 39, n. 7, p. 4222-4234, 2011.

CARVALHO, P. Compra de usinas endividadas substitui construção de novas unidades. $I G$, São Paulo. 23/01/2012. Disponível em: <http://economia.ig.com.br/ compra-de-usinas-endividadas-substitui-construcao-de-novas-unida/n1597588033829.html>. Acesso em: 11 fev. 2013.

CENTRO DE GESTÃO E ESTUDOS ESTRATÉGICOS (CGEE). Bioetanol combustível: uma oportunidade para o Brasil. [On-line] CGEE, 2009. Disponível em: <www.cgee.org.br>. Acesso em: 27 fev. 2013.

COMPANHIA NACIONAL DE ABASTECIMENTO (CONAB). Perfil do setor do açúcar e do álcool no Brasil: edição para a safra 2009-2010. [On-line] CONAB, 2012a. Disponível em: $<$ www.agricultura.gov.br>. Acesso em: 22 fev 2013.

COMPANHIA NACIONAL DE ABASTECIMENTO (CONAB). Acompanhamento de safra brasileira: cana-de-açúcar. Terceiro levantamento, dezembro/2012. Brasília: Conab, 2012b.

COMPANHIA NACIONAL DE ABASTECIMENTO (CONAB). A geração termoelétrica com a queima do bagaço de cana-de-açúcar no Brasil: análise do desempenho da Safra 2009-2010. [On-line] CONAB, 2011. Disponível em: <www.agricultura.gov.br>. Acesso em: 22 fev. 2013.

COMPANHIA NACIONAL DE ABASTECIMENTO (CONAB). Perfil do setor do açúcar e do álcool no Brasil: edição para a safra 2007-2008. [On-line] CONAB, 2008. Disponível em: $<$ www.agricultura.gov.br>. Acesso em: 22 fev. 2013.

FINANCIADORA DE ESTUDOS E PROJETOS (FINEP). PAISS. [On-line] Finep. Última atualização 19 jun. 2013. Disponível em: <http://goo.gl/1bJWSt>. Acesso em: 17 jun. 2015.

GARCIA, J. R. O Programa Nacional de Produção e Uso de Biodiesel Brasileiro e a Agricultura Familiar na Região Nordeste. Dissertação de Mestrado, Instituto de Economia, Universidade Estadual de Campinas, Campinas, 2007. 
GOLDEMBERG, J.; LUCON, O. Energia e meio ambiente. Estudos Avançados, v. 21, n. 59, 2007.

GREGORY, D.; OLIVEIRA, M. O desenvolvimento de ambiental favorável no Brasil para a atração de investimento estrangeiro direto. 2005. Disponível em: <www.wilsoncenter.org/sites/ default/files/brazil.atracaodeIED.pdf>. Acesso em: 28 fev. 2013.

GUIMARÃES, E. A. A. Organização industrial: a necessidade de uma teoria. Pesquisa de Plan. Econ., v. 9, n. 2, p. 517-530, 1979.

KOHLHEPP, G. Análise da situação da produção de etanol e biodiesel no Brasil. Estudos Avançados, v. 24, n. 68, 2010.

LIMA, D. A. L. L.; RAMOS, P. Dinâmica da Expansão e Consolidação da Vale do Verdão S/A Açúcar e Álcool em Goiás. In: Congresso Brasileiro de História Econômica e Conferência Internacional de História de Empresas, 8, Campinas, SP, 6-8 set., 2009. Anais... Campinas: Unicamp, 2009.

LIMA, D. A. L. L.; GARCIA, J. R.; VIEIRA, A. C. P.; SILVEIRA, J. M. F. J. A inserção de inovação e o novo padrão de produção da agroindústria canavieira: estudo de caso na Usina Goiasa - Goiás. Espacios, Caracas, v. 33, p. 1-20, 2012.

LEAL, M. R. L. V. Evolução tecnológica do processamento da cana-de-açúcar para etanol e energia elétrica. In: CORTEZ, L. A. B. (Coord.) Bioetanol de cana-de-açúcar: PઐD para produtividade e sustentabilidade. São Paulo: Blucher, 2010, p. 561-575.

JULCA-BRICEÑO, B. M.; PINTO, M. J. A.; NEVES, M. F. Internationalization of Brazilian Sugar-Energy Industry: Market Analysis of Colombia and Peru. In: International Food and Agribusiness Management Association, IAMA, \& 20th Annual World Forum and Symposium - Navigating the Global Food System in a New Era, 2010, Boston, Estados Unidos. Disponível em: <http://www.ifama.org>. Acesso em: 22 fev. 2013.

KOIZUMI, T. The Japanese biofuel program - Developments and perspectives. Journal of Cleaner Production, v. 40, p. 57-61, 2013.

MINISTÉRIO DA AGRICULTURA, PECUÁRIA E ABASTECIMENTO (MAPA). Anuário Estatístico da Agroenergia: 2012. [On-line] MAPA, 2013. Disponível em: <www.mapa.gov.br>. Acesso em: 22 fev. 2013.

MARCEDO, I. Situação atual e perspectivas do etanol. Estudos Avançados, v. 21, n. 59, 2007.

MORAES, B.; RAMOS, H. R.; SOARES, M. C.; ALMEIDA, M. I. R. Fatores determinantes para a entrada de Investimento Estrangeiro Direto no setor sucroalcooleiro do Brasil. In: Congresso Internacional de Estratégia SLADE, 23, Guayaquil, Equador, 2010. Anais... Guayaquil: SLADE, 2010, v. 1. p. 1-23.

MORAES, M. A. F. D.; SHIKIDA, P. F. A. (Orgs.) Agroindústria canavieira no Brasil: evolução, desenvolvimento e desafios. São Paulo: Atlas, 2002.

NASTARI, G. Capital estrangeiro cada vez mais forte. AgroAnalysis, Agroenergia, FGV/EESP, abr. 2010. Disponível em: <http://www.agroanalysis.com.br/materia_detalhe.php?idMateria $=825>$. Acesso em: 13 fev. 2013.

NORTH, D. Institutions. Journal of Economic Perspectives. v. 5. n. 1, p. 97-112, 1991.

Nyko, D.; Garcia, J. L. F.; Milanez, A. Y.; Dunham, F. B. A corrida tecnológica pelos biocombustíveis de segunda geração: uma perspectiva comparada. BNDES Setorial, Biocombustíveis, n. 32 , p. 5-48, 2010. 
NYKO, D.; VALENTE, M. S.; DUNHAM, F. B.; MILANEZ, A. Y.; COSTA, L. M. DA; PEREIRA, F. DOS S.; TANAKA, A. K. R.; RODRIGUES, A. V. P. Planos de fomento estruturado podem ser mecanismos mais eficientes de política industrial? Uma discussão à luz da experiência do PAISS e seus resultados. BNDES Setorial, Inovação, n. 38, p. 55-78, 2013.

PINTO, M. J. A. Investimentos diretos estrangeiros no setor sucroenergético. Dissertação de Mestrado, Faculdade de Economia, Administração e Contabilidade, Universidade de São Paulo, Ribeirão Preto, SP, 2011.

SCHENBERG, A. C. G. Biotecnologia e desenvolvimento sustentável. Estudos Avançados, v. 24, n. 70, 2010.

SINDICATO DA INDÚSTRIA DA FABRICAÇÃO DO ÁLCOOL NO ESTADO DE MINAS GERAIS (SIAMIG). Capital estrangeiro no setor sucroalcooleiro brasileiro. Relatório Econômico, no 007, Belo Horizonte, Minas Gerais, 28 jan. 2009. Disponível em: < www.udop. com.br/download/.../2009/04_02_relatorio_siamig.pdf>. Acesso em: 28 fev. 2013.

SIQUEIRA, P. H. de L.; CASTRO JÚNIOR. L. G. Fusões e aquisições das unidades produtivas e da agroindústria de cana-de-açúcar no Brasil e nas distribuidoras de álcool hidratado etílico. RESR, Piracicaba, SP, v. 48, n. 4, p. 709-735, out./dez. 2010.

SCHMALENSEE, R.L. Industrial Economics: An Overview. Working Paper, Alfred P. Sloan School of Management, MIT, 1988.

SORDA, G; BANSE, M.; KEMFERT, C. An overview of biofuel policies across the world. Energy Police, v. 38, p. 6977-6988, 2010.

TYE, Y. Y. ET AL. Second-generation bioethanol as a sustainable energy source in Malaysia transportation sector: Status, potential and future prospects. Renewable and Sustainable Energy Reviews, v. 15, n. 9, p. 4.521-4.536, 2011.

UNIÃO DA INDÚSTRIA DE CANA-DE-AÇÚCAR (ÚNICA) Movimento + etanol. [On-line] ÚNICA, 2011a. Disponível em: <www.unica.com.br>. Acesso em: 13 fev. 2013.

UNIÃO DA INDÚSTRIA DE CANA-DE-AÇÚCAR (ÚNICA). Key numbers of the Brazilian Sugar cane Industry: 2010/2011 harvest. [On-line] ÚNICA, 2011b. Disponível em: <www. unica.com.br>. Acesso em: 13 fev. 2013.

VARIAN, H. R. Intermediate microeconomics: a modern approach. 3 ed. New York: Norton, 1993.

WATANABE, M. A desregulamentação do setor sucroalcooleiro e seu impacto na estratégia de produção das usinas no estado do Paraná. Dissertação de Mestrado, Escola de Administração, Universidade Federal do Rio Grande do Sul, Porto Alegre, RS, 2001. 